\title{
Article \\ A Systematic Review of Design Creativity in the Architectural Design Studio
}

\author{
Hernan Casakin ${ }^{1, *(1)}$ and Andrew Wodehouse ${ }^{2}$ \\ 1 School of Architecture, Ariel University, Ariel 40700, Israel \\ 2 Department of Design, Manufacture and Engineering Management, University of Strathclyde, \\ Glasgow G1 1XJ, UK; andrew.wodehouse@strath.ac.uk \\ * Correspondence: casakin@ariel.ac.il
}

check for updates

Citation: Casakin, H.; Wodehouse, A. A Systematic Review of Design Creativity in the Architectural Design Studio. Buildings 2021, 11, 31. https: / / doi.org/10.3390/ buildings11010031

Received: 16 December 2020 Accepted: 13 January 2021 Published: 17 January 2021

Publisher's Note: MDPI stays neutral with regard to jurisdictional clai$\mathrm{ms}$ in published maps and institutional affiliations.

Copyright: (C) 2021 by the authors. Licensee MDPI, Basel, Switzerland. This article is an open access article distributed under the terms and conditions of the Creative Commons Attribution (CC BY) license (https:// creativecommons.org/licenses/by/ $4.0 /)$.

\begin{abstract}
Creativity is fundamental to design problem-solving. This paper sets out a systematic review of the literature in relation to its role in the architectural design studio in order to identify central issues that impact upon this activity. Challenges and best practices in relation to systematic reviews are outlined, and the procedure followed in this context is set out in detail. This involves an iterative evaluation process that resulted in a pool of 17 papers for analysis. Eleven themes emerged in the analysis of the papers, which were organized into five key categories dealing with: pedagogy, cognitive approach, interaction and socialization, information representation, and measuring ideation and creativity. A discussion of these categories contributed to the comparison and connections between the selected papers, and the identification of critical issues and directions for promoting creativity in the architectural design studio.
\end{abstract}

Keywords: creativity; ideation; architectural design studio; education; systematic review

\section{Introduction}

Creativity constitutes an important topic related to design problem-solving. Most design problems are ill-defined and, therefore, cannot be completely solved using routine problem-solving processes, either manually or computationally [1,2]. A characteristic of design problems is that they are complex, ambiguous, and unique [3]. Because of the nonroutine and ambiguous nature of design problems, it is not possible to foresee what type of information will lead to what kind of solutions. Hence, tackling design problems implies the generation of many different and potentially creative ideas and unpredictable solutions [4].

Creative thinking can aid to enrich and develop the abilities needed to tackle illdefined processes, and generate exceptional solutions $[5,6]$. To this aim, creative ideas and concepts should be first generated [7-9]. Although idea generation is of primary relevance at the early stages in terms of defining configuration and form, and it is considered the most creative phase of the design process, it continues to be of importance through the embodiment and detailing stages [10]. The integration of creative practices and methods has therefore become an increasing priority in industry for designing products $[11,12]$ in order to allow companies to capture a larger market share [13].

While creativity was traditionally considered as a domain-general ability [14,15], recently it started to be viewed as domain-specific. This means that the generation of creative outcomes implies an ability that should be domain-content (e.g., [16,17]). However, other researchers maintained that the two notions are related $[18,19]$. For example, Casakin et al. [20], who carried out a study in architectural design, found that the generation of creative idea solutions in a specific domain can benefit from both high general and specific creative thinking abilities.

While design creativity has been studied in a variety of fields, such as engineering and industrial design, in this work we focus on architecture. Several studies showed 
that architectural design is a highly relevant domain for the study of creativity [21,22]. Therefore, the present work offers an overview of creativity issues and approaches used in the architectural domain, with a main focus set on the architectural design studio.

The promotion and enhancement of creativity is a fundamental aspect of architectural studies, and its stimulation has greatly influenced the development of educational programs and the teaching in the design studio [23]. In fact, the most important experience of the architectural schools and departments is the design studio. It is in this educational setting where the students acquire some of the most critical knowledge and design skills, and develop their creativity [24]. They experiment with problems simulating real-life practice, while gaining experience in integrating theoretical with practical aspects of the architectural profession [25]. This paper therefore reviews the issues that have arisen in the literature with respect to design problem solving in the architectural studio and its relation to the generation of creative idea solutions. Creativity is no longer considered to be simply an innate ability, but a tendency that can be nurtured and applied in a more systematic manner. To that end, there are a range of theoretical models on the cognitive manifestation of creativity and accompanying procedural methods, as well as plethora of support environments, strategies, and tools to support creative activity [26]. These are, to some extent, more established in the engineering and industrial design domains where highly specific approaches such as the use of humor within existing design methods [27] have been explored. The value of similarly procedural approaches to creativity is becoming recognized in architecture [28], and as such, a review to understand the current landscape and areas of development is timely.

In this paper, we used a systematic literature review to document the issues related to creativity and ideation activity identified as relevant to the architectural design studio [29]. This provides a degree of transparency in the sourcing, evaluation and synthesis of results, and is deemed appropriate to capture the current state-of-the-art in this domain.

We structured the paper as follows. The Materials and Methods section outlines the nature and requirements of a systematic review, and after setting out the derivation of the research question, it details the extraction, analysis, and presentation of data [30]. The Results section describes the content of the 17 papers identified and analyzed according to study categories. The discussion section addresses critical issues based on the different themes identified through the papers, and implications for enhancing creativity in the architectural design studio. In the Conclusions, main considerations derived from the study findings, and future research directions are presented.

\section{Materials and Methods}

Systematic literature reviews utilize defined scoping criteria, search terms, and analysis protocols in order to provide an explicit overview of the topic of focus [31,32], and transparency in how the review findings are derived [33,34]. A methodical set of steps are necessary in order to define scope, search and evaluation criteria, literature sources, and appraisal of results [35].

A key challenge in this context is that the topic of creativity is extremely broad and systematic reviews tend to be applied in technical areas where it is easy to quantify different characteristics. For example, the Problem, Intervention, Comparison, Outcome (PICO) framework [36] is often used to help ensure that key parameters are identified in relation to the research question and to shape the analysis for systematic reviews. While this tends to lend itself to specific technical interventions, in the present study, it has been adapted as shown in Table 1 to represent aspects relevant for the present study, such as key population, intervention, context, and outcome issues.

While they can vary in their scope, the incorporation of critical assessment and strategies for synthesis are critical to the delivery of meaningful results [37-39]. Given the qualitative nature of much of the literature relating to creativity in the architectural design studio, and the limited number addressing this context, we report on a detailed evaluation and assessment protocol that considers the papers against a range of criteria. In critiquing 
and appraising the search results, Tondeur [40] sets out an approach to the derivation of themes based on exploration of sources retrieved. This is effective in identifying emerging issues, and has thus been adopted to support interpretation of the papers and development of the discussion.

Table 1. Problem, Intervention, Comparison, Outcome (PICO) framework for creativity in the architectural design studio.

\begin{tabular}{|c|c|c|}
\hline Framework Component & Definition & Description \\
\hline Population & Students & $\begin{array}{l}\text { Activity undertaken by students as part } \\
\text { of their architectural education. }\end{array}$ \\
\hline Intervention & Design activity & $\begin{array}{l}\text { Focus on the earlier stage of the design } \\
\text { process where methods, tools, models or } \\
\text { frameworks support ideation. }\end{array}$ \\
\hline Context & Architectural studio & $\begin{array}{l}\text { Activity by both architectural students } \\
\text { and teachers in the studio setting. }\end{array}$ \\
\hline Outcome & Creativity issues & $\begin{array}{l}\text { The potential impact of creativity that can } \\
\text { be considered in many ways, e.g., } \\
\text { confidence of participants, rated quality } \\
\text { of concepts. }\end{array}$ \\
\hline
\end{tabular}

\subsection{Research Question}

From the background issues identified above, a research question was derived. Based on experimentation with different terminology, it was apparent that papers were not abundant, and therefore a highly defined question was not appropriate. Significant time was invested in looking for an appropriate level of refinement in order to carry out a systematic literature review embracing a satisfactory number of papers to be analyzed in respect to the question under consideration. There were also a number of technical and academic issues that influenced the definition of the research question. These included the specificity of the domain-i.e., the architectural design studio-meaning that the terminology had to be sufficiently broad, as there is not the same developed tradition of scientific work with regards to creative practices in architecture, as in other fields, such as engineering or industrial design. Consequently, our systematic literature review is aimed to answer the following research question:

"What creativity and ideation issues exist during design activity carried out in the architectural studio?"

\subsection{Data Extraction}

The principal tool used for the retrieval of papers was Summon. This is one of the most comprehensive metasearch engines that interfaces with academic libraries, as well as facilitating search for external peer reviewed material such as books and journal articles. It spans a significant set of databases, thereby allowing a high volume of material to be retrieved without visiting multiple sources. Search results can be conveniently refined and narrowed down by using filters such as content type (e.g., journal article, book review, conference proceeding), subject terms, publication date, language, and more. In critically scanning the initial content of the sources [41], and based on the experience of the authors, it was decided to include additional searches in the Scopus database and across key Design Society-affiliated publications (See Table 2). These are known leading journals containing areas of knowledge where significant bodies of work have been consolidated in relation to the engineering, industrial, and architectural design domains.

\subsection{Identification of Relevant Literature}

The strategy to construct the search string follows that set out by Salleh et al. [31]. This involved: 
- Deriving major terms used in the research question (i.e., based on the population, intervention, context, and outcome).

- $\quad$ Listing the keywords mentioned in the articles (related studies) we knew about before starting this review.

- Searching for synonyms and alternative words.

- Using the Boolean OR to incorporate alternative spellings and synonyms.

- Using the Boolean AND to link the major terms from population, context, and outcome.

- Using an asterisk "*" as a wildcard operator.

Table 2. Table outlining the databases and search terms utilized.

\begin{tabular}{cc}
\hline Database/Journal & No. of Papers \\
\hline Summon & 478 \\
Scopus & 61 \\
Journal of Engineering Design & 2 \\
Design Studies (modified terms) & 62 \\
CoDesign & 18 \\
Research in Engineering Design & 6 \\
International Journal of Design Creativity and Innovation & 3 \\
Design Science & 118 \\
\hline
\end{tabular}

Following a significant degree of experimentation, the final search string used for the searching of the literature was:

$$
\text { creativ* AND architect* AND ("design studio") AND (idea* OR concept*) }
$$

Initial searches based on the Summon search engine using broad terms such as "design creativity" resulted in a huge number of results that, even after filtering, were too diverse and numerous for review. An alternative approach was then adopted with a comprehensive list of well-known methods and tools for enhancing creativity (e.g., brainstorming, Theory of Inventive Problem Solving (TRIZ), metaphorical thinking) utilized explicitly in the search string. This, however, resulted in a very limited pool of results when linked to the architectural domain. The final search term presented above represented the population, intervention, context, and outcome, and provided a manageable number of results (717) with a good degree of relevance. A discipline filter was further applied, limiting the papers returned to the fields of: architecture, business, computer science, education, engineering, and psychology (excluding irrelevant areas such as chemistry, law, or public health). This reduced the number of results to 478 and provided an appropriate balance between breadth and focus in the pool or papers for review.

\subsection{Selection of Studies}

Our inclusion criteria aimed to only include empirical studies that targeted architectural design education and focused on creativity and ideation. Consequently, the literature search only covered those works published under these considerations at any period of time. The main exclusion criteria were related to papers that: did not target these issues; had claims by the author(s) without empirical supporting evidence; involved students outside the context of the architectural design studio; were not written in English; were published in unrefereed journals; were conference papers.

\subsection{Data Extraction and Study Quality Assessment}

An overview of the systematic process adopted, and the statistics for papers gathered, screened and reviewed at each stage, is shown in Figure 1. In the first searching stage of the selection process, the primary studies based on the titles, abstracts, and keywords were analyzed by the two authors independently of one another. When the data extracted differed, such disagreements were discussed in a reviewing session until consensus was reached. 
No inter-rater agreement was measured provided that the review session aimed to reach a full consensus on the sample used [42]. In a second screening stage, in order to facilitate the data extraction process, a form was designed and used to collect evidence relating to the research question, and measure the quality of the full paper of the pre-selected studies. Our checklist focused on relevance, clarity and data according to the following ratio scale: Yes $=1$ point; $\mathrm{No}=0$ points; and partially $=0.5$ points. The resulting total quality score for each study ranged between 0 (very poor) and 2 (very good). Both authors, independently of one another, were responsible for reading and applying the checklist to the pre-selected studies. In order to validate the data extraction process, a random sample comprised of approximately $20 \%$ of the total number of primary studies were extracted and analyzed by the first and second authors, and then compared in a review meeting. The remaining $80 \%$ of primary studies was randomly divided in two halves, and analyzed by each author independently. It was expected that the lessons taken from the review meeting would reduce the bias for data extraction. In the appraisal stage, an identical process was followed, although the checklist was adapted to focus on scope, analysis and significance. At this stage, the emerging themes were formulated based on discussion around the content of selected papers. In the final synthesis stage, the papers were reviewed in depth against the themes, until full agreement was reached by both authors in a final review meeting.

Summon

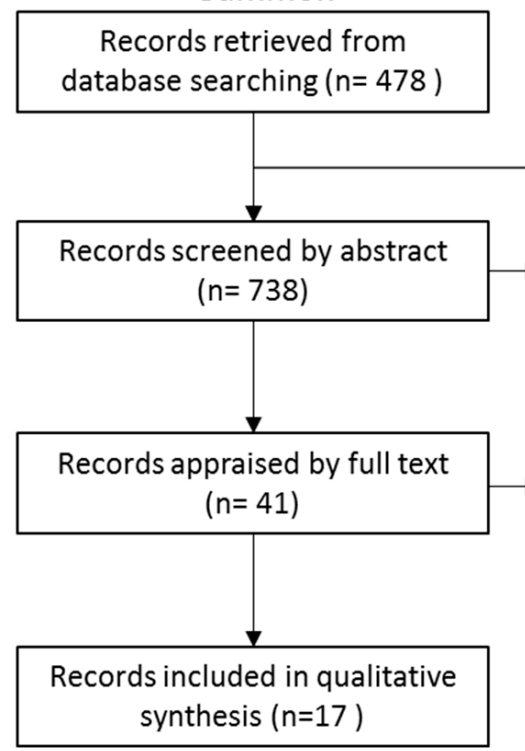

Scopus

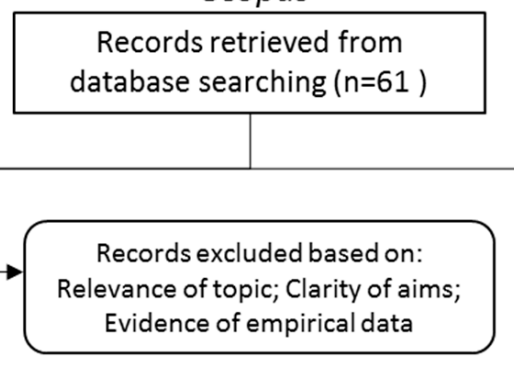

Records excluded based on: Scope of study; Formulation of analysis; Significance of insights
Distributed between two reviewers based on expertise, reviewed against emerging themes, and compared and discussed for applicability
Independent assessment of applicability by two reviewers [Yes/No/Partially] with ranking and discussion to consolidate

Distributed between two reviewers randomly and assessed for applicability [Yes/No/Partially], with ranking, comparison and discussion to consolidate

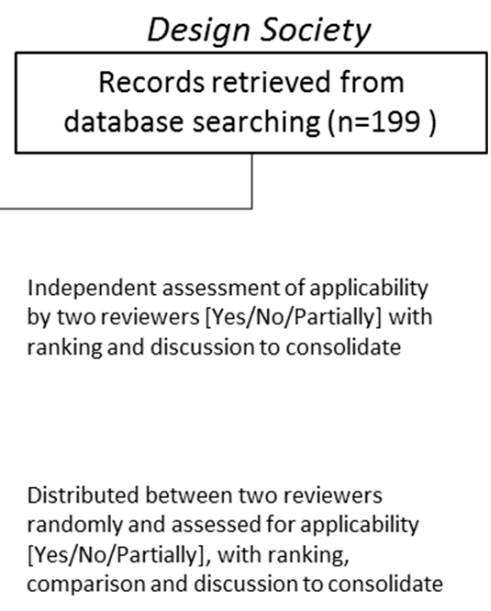

\section{.}

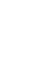


eleven themes were identified. The categories included Pedagogy, Cognitive approach, Interaction and socialization, Representations: models and tools, and Measuring ideation and creativity. These span both practical considerations conducive to creative activity in the architectural design studio, as well as theoretical models and frameworks that underlie interpretations of creativity in this context. The themes associated with each category, as well as the papers that directly addressed them are depicted in Table 3, with the papers ordered alphabetically by lead author and an " $\mathrm{X}$ " indicating that this theme was directly addressed. The remainder of this section is organized according to the categories, with discussion of each of the themes aligned under each.

Table 3. Categories and themes emerging for the selected papers.

\begin{tabular}{|c|c|c|c|c|c|c|c|c|c|c|c|c|c|c|c|c|c|c|}
\hline & Theme & 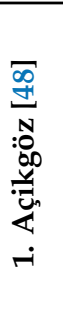 & 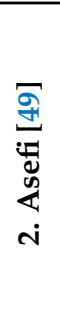 & 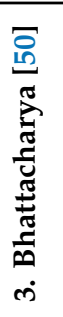 & 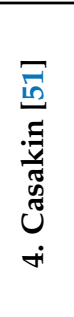 & 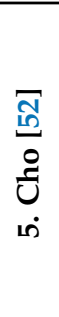 & $\begin{array}{l}\bar{N} \\
\stackrel{0}{0} \\
\bar{\sigma} \\
\dot{U} \\
0\end{array}$ & 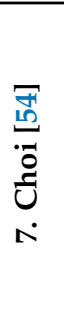 & 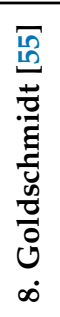 & 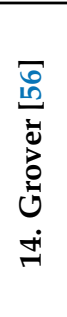 & 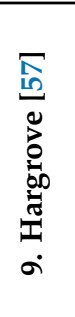 & 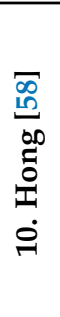 & 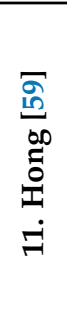 & 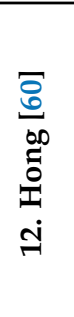 & 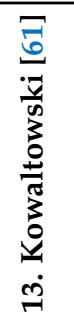 & 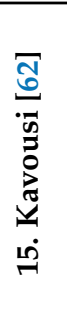 & 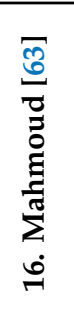 & 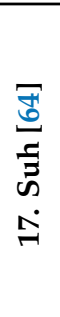 \\
\hline I & Pedagogy & & & & & & & & & & & & & & & & & \\
\hline 1 & $\begin{array}{l}\text { Training for } \\
\text { creativity }\end{array}$ & & $X$ & & & & $x$ & & & $x$ & $x$ & $x$ & $x$ & $x$ & $x$ & & & \\
\hline 2 & $\begin{array}{l}\text { Structuring design } \\
\text { processes and } \\
\text { problems }\end{array}$ & $x$ & $X$ & $x$ & $x$ & & $x$ & $x$ & $X$ & $x$ & $x$ & & $x$ & & $x$ & $x$ & & $x$ \\
\hline II & $\begin{array}{l}\text { Cognitive } \\
\text { approach }\end{array}$ & & & & & & & & & & & & & & & & & \\
\hline 1 & Reflection & $x$ & $\mathrm{X}$ & & & & $x$ & $\mathrm{X}$ & $\mathrm{X}$ & & $x$ & $\mathrm{X}$ & $x$ & $x$ & $x$ & $x$ & & \\
\hline 2 & $\begin{array}{l}\text { Design strategies } \\
\text { and methods }\end{array}$ & & & $x$ & & & $x$ & & & $x$ & $x$ & $x$ & $x$ & $\mathrm{x}$ & $x$ & $x$ & $x$ & $x$ \\
\hline 3 & $\begin{array}{c}\text { Information } \\
\text { processing }\end{array}$ & & & & & $x$ & $x$ & $x$ & $x$ & & $x$ & & & & & & & $x$ \\
\hline III & $\begin{array}{l}\text { Interaction and } \\
\text { socialization }\end{array}$ & & & & & & & & & & & & & & & & & \\
\hline 1 & Collaboration & & & & & & $x$ & $x$ & $x$ & & & & $\mathrm{x}$ & & & & & \\
\hline 2 & $\begin{array}{c}\text { Shared mental } \\
\text { models and stimuli }\end{array}$ & $x$ & & & & & & $x$ & & & & & & & & & & \\
\hline IV & $\begin{array}{l}\text { Information } \\
\text { representation } \\
\text { Tools for }\end{array}$ & & & & & & & & & & & & & & & & & \\
\hline 1 & $\begin{array}{l}\text { information } \\
\text { representation }\end{array}$ & $x$ & & $x$ & & & & & $X$ & $x$ & $x$ & $x$ & & $\mathrm{x}$ & & & & $x$ \\
\hline 2 & $\begin{array}{l}\text { Manipulation of } \\
\text { information }\end{array}$ & & & & & $X$ & & & & $x$ & & $x$ & & $x$ & & & & \\
\hline $\mathbf{V}$ & $\begin{array}{l}\text { Measuring } \\
\text { ideation and } \\
\text { creativity }\end{array}$ & & & & & & & & & & & & & & & & & \\
\hline 1 & $\begin{array}{l}\text { Assessment of } \\
\text { creative processes } \\
\text { and problems }\end{array}$ & $x$ & $X$ & & $x$ & $x$ & $x$ & $x$ & $x$ & $x$ & $x$ & $x$ & & $\mathrm{X}$ & & $x$ & $x$ & $x$ \\
\hline 2 & $\begin{array}{l}\text { Assessment of } \\
\text { personal abilities }\end{array}$ & & & $\mathrm{x}$ & & $x$ & & & & & & & & & & $x$ & $x$ & \\
\hline
\end{tabular}




\subsection{Category I: Pedagogy}

The first category of pedagogy addresses issues concerned with teaching creativity in the architectural design studio context. This has been highlighted as integral in preparing self-sufficient and innovative future architects [49], and to this end we have identified two sub-categories. Firstly, the general provision of training with respect to creativity, and secondly the structuring of processes and problems to support creative teaching.

\subsubsection{Training for Creativity}

Research aimed at training design students in the architectural design studio context with regard to creativity issues is limited. Hargrove and Nietfeld [57] explored the effectiveness of teaching creativity in the form of associative thinking strategies. The pedagogical approach aimed at assisting creative problem solving, and consisted of integrating activities related to creative thinking strategies to encourage the development of metacognitive skills. The idea was that creative thinking is an ability that can be trained, and developed over time. Grover et al. [56] designed a series of workshops aimed at teaching students how to systematically use typologies. The training environment was intended to learn how to: categorize and transform primary generators, such as images, into defined conceptual types; retrieve and adapt different typologies based on precedents to produce spatial diagrams; and to associate projects with building types and elaborate consistent strategies for further progressing in the design process. Students reported that the systemic typologies were the most valuable workshop, where they gained skills to extract and adapt spatial knowledge from a selection of precedents. The underlying idea of the approach of Bhattacharya et al. [50] was that active exposure to unusual experiences and/or situations can have useful creativity-enhancing applications in the design studio. Their pedagogical approach was based on the idea that conceptual blending in virtual scenarios can be used for boosting and training divergent thinking, while dealing with a variety of unfamiliar and unexpected design situations. The approach was successful in preventing the use of conventional stereotypes and rules, and in reducing the process of losing creative thinking.

\subsubsection{Structuring Design Processes and Problems}

Kowaltowski et al. [61] reviewed creativity methods and their use in the design studio from an instructor's perspective. The results of interviews with 28 design instructors on applicable methods for the design studio report that methods are typically applied in an unstructured manner and would benefit from a more systematic approach. Asefi and Imani [49] consider more broadly the "mode shifting" needed to accommodate the different types of thinking required at different stages of the design process. Using a comparative study of student output, they advocate an Active Strategic Teaching Model (ASTM) under which different tools and methods would be assigned for use in design studio work. With the aim of guiding students at the different stages of the design process, Grover et al. [56] used historical theories of typology as a structured framework for the retrieval of knowledge contained in architectural building precedents. The design stages included frame definition, concept design and the development of a detailed project. Choi and Kim [53] advocate that learners are asked to consider the reconstitution of design problems from multiple perspectives, suggesting that this can improve expansion of the solution space. Their proposed approach involves the use of abstraction at beginning of the design process to help articulate and reflect upon on the context.

Goldschmidt and Tatsa [55] analyze student ideas generated during the development of their design studio projects, together with further ideas constructed by both fellow students and instructors. Their approach allowed to gain a deep insight onto how ideas are structured along the design process in regard to not only quantity but also quality. Kavousi et al. [62] propose a conceptual model that focuses on the role of metacognitive processing in design education regarding the student's design thinking and making. Their study shows the way that components of metacognition interact, and how they can support educational programs looking to improve the design process and the produced 
creative outcomes. In their study, Mahmoud et al. [63] found that at the beginning of the process, students were able to tolerate uncertainty and ambiguity, what helped them to produce multiple ideas. This was possible since, at this stage of the process, they succeeded to deal with doubts and un-clarity without seeking for certainties of facts. In contrast, ambiguity aversion was not related to student creativity at the second phase of the design process, characterized by convergent thinking; hence, they ended with more conventional solutions. These researchers concluded that tolerance of ambiguity was fundamental in the phase of generating creative ideas but not so much in the selection of them.

Suh and Cho [64] explored the relation between individual cognitive styles and creative performance by structuring the design process according to phases, such as initial design, combinational ideation process, combination process, and final design. The students' creative performance was studied at the initial and final stages. They found that intuitive students were more creative at the initial phase; in contrast, adaptive and more analytical ones enhanced their creativity at the final phase of the process. These researchers maintained that design educators can benefit from this instruction method to help nonintuitive students in particular improve their ideation process. Contrasting differences were observed by Casakin and Kreitler [51] while comparing the way that students and teachers explored design creativity processes and outcomes. They found that while students centered on operational aspects, teachers paid more attention to innovative aspects of process and outcomes by the students. They concluded that intervention programs in the design studio might consider these differences in order to promote the acquisition of design procedures, as well as to gain a deeper insight into how to bridge the gap regarding the way that students compared to teachers perceive design creativity.

\subsection{Category II: Cognitive Approach}

The second category focuses on cognition and creativity aspects studied in the architectural design studio. Kowaltowski et al. [61] assert that problem-solving capacity is dependent on two cognitive factors-repertoire (background knowledge pertaining to the context) and heuristics (the systemization of insights). We further delineated this interpretation of repertoire to account for personal reflection-which has emerged as particularly relevant to metacognitive theory-and the processing of external information, which is essential for creativity in technical contexts.

\subsubsection{Reflection}

Choi and Kim [54] describe fixation as a persistent problem in creative design, and argue that a means to break this kind of limitation is to bypass normal physical and mental constraints, freeing imagination through the use of digital worlds and abstract design tasks. Weekly diaries kept by architectural design students supported these assertions. Hargrove and Nietfeld [57] examined the extent to which a metacognitive reflection approach enables designers to construct explicit mental models for applying creative thinking knowledge and skills to a variety of design problems. Their study investigated the use of associational strategies, by means of which students were encouraged to enhance their understanding of their own cognitive processes, how to control and apply their problemsolving processes, and how to develop their skills to generate creative problem-solving ideas and solutions in order to tackle design problems.

The model proposed by Acikgoz [48] to promote reflexivity during design problem solving connects the Collaborative Sketching (C-Sketch) technique and the Ideas, Connections and Extensions (ICE) approach. In the latter, ideas, connections, and extensions refer to improved learning which is concerned with the level of expertise of the student. The content of the ideas about a specific problem is connected, integrated, and adapted and given a new meaning. In such a model, encouraging critical reflection is intended to enforce the possibility of students' self-assessment and the structuring during all the decision instances of the design processes. To this aim, design decisions are recorded to enable monitoring their consistency along the process. In the conceptual model by 
Kavousi et al. [62], design is understood as a process where students construct their own reality through ad hoc design actions, which are responsive, opportunistic, and reflective to the design situation under consideration. These authors developed a categorization system for better understanding a variety of reflective metacognition processes in support of ideation and creative thinking.

\subsubsection{Design Strategies and Methods}

Research in relation to design strategies and methods is moving beyond the derivation and application of methods to understand more widely where these are desirable, and how they interact with cognitive processes. After reviewing a range of methods, approaches, such attribute lists, TRIZ, brainstorming, mental maps, and biomimicry, Kowaltowski et al. [61] suggest analogy is one of the most popular and particularly beneficial for "integrating meaning and communication". Choi and Kim [53] conducted a direct comparison of analogical and metaphorical reasoning in design to support creative thinking. This was deemed desirable to encourage students to break from conventional thinking and prior examples. Architectural design students were asked to utilize different methods, with the findings suggesting that unconventional and "formless" stimuli could encourage analogical and metaphorical reasoning respectively. The authors conclude that careful selection of methods with appropriate support material can greatly enhance self-motivation in the design studio. In the study by Hargrove and Nietfeld [57], a representative sample of students from a larger design course were requested to practice strategies that highlighted associative thinking and emphasize metacognitive knowledge and thinking skills. This treatment group was compared with other students from the introductory design course on measures of creative problem solving that stressed associative thinking.

Grover et al. [56] combine a hierarchical typological structure with a phase-based model of the design process to investigate the way into which typologies as major strategies can support the design process as the project develops and augments its definition. Metaphorical typologies are considered in the frame definition stage, systemic typologies are used as consistent organizational strategies in the concept design phase, whereas elemental typologies are employed at the detail phase to identify, transfer and adapt components and conditions contained in precedents. These are seen as well-known examples of architectural buildings designed by master architects from which a lesson can be learned. They found the typological approach to be effective for accessing information embedded in design precedents and for encouraging idea generation at all design stages. Bhattacharya et al. [50] developed a method called "Proto-Fuse" aimed at navigating in unconventional virtual environments (UVEs) for enhancing cognitive perception in support of spatial creativity. The method was conceived for transiently altering our visual environment in order to encourage the psychological functions of conceptual blending and tolerance of ambiguity, both aimed to boost creative thinking. The generation of new ideas was encouraged following the belief that conceptual blending mutation in the unconscious mind will contribute to improve creativity.

\subsubsection{Information Processing}

In established contexts, such as architecture, where it is important to be aware of history, precedent and technical fundamentals, the effective integration of external information to inform conceptualization is a key consideration. A design thought model based on students' self-reporting was employed by Hargrove and Nietfeld [57] to monitor and control the process in the application of the associational strategy. The model included a number of tools such as a strategy evaluation matrix, a regulatory checklist, a metacognitive mental model matrix, and a personal reflection journal, which showed to be efficient to assist students in monitoring their ability to processing information within an educational intervention framework that supported metacognitive strategy instruction and regulation. Focusing on the designers' different information processing styles, Suh and Cho [64] proposed combinational ideation as an approach to guide students during the ideation process. 
This was found to motivate students to self-generate new ideas by combining different concepts, ideas, or elements of their designs.

Based on the critical method that views design as a cyclical process (e.g., Wright [65], Lydon and Garcia [66]), Grover et al. [56] employ a hierarchical typological structure to analyze information and support decisions taken along main stages of the design process. Information was processed through an iterative process of initial conjectures, identification, formation, and analysis of typological knowledge, their relation and application to the conjectures, and a test stage. Moreover, at a cognitive level, Goldschmidt and Tatsa [55] inspected the links produced among small units of thought known as "design moves", which are deployed in a few seconds. These researchers also explored different types of ideas generated in the design process, and links established among them. An underlying proposal was that creative processes are the outcome of an interweaving and articulation of a complex set of interrelated steps, rather than of unconnected moves. They differentiated between ideas that did not have an impact or impacted negatively to the project, and significant critical ideas considered to have a major contribution. The latter were found to have the largest number of links to other moves or ideas generated during the design process. Cho [52] focused on the importance of spatial ability in design problem solving. Specifically, he investigated the relation of this construct and student visual cognitive styles, creativity, and the design studio performance, measured by the obtained scores. His study contributed to the development of a meaningful pedagogy aimed at identifying which abilities need to be prioritized, encouraged, and nurtured.

\subsection{Category III: Interaction and Socialization}

Creativity in educational contexts is not just a matter of internal deliberation, but also how teams can effectively share and communicate their ideas. The many advantages of collaborative approaches to creativity are established in the literature. Alongside this, we identified an emerging line of research in terms of how multiple student designers can develop a shared understanding of design while working together.

\subsubsection{Collaboration}

Collaborative creative sessions, which broadly fall under the umbrella of brainstorming, are amongst the most prevalent techniques used by teams of students for the generation of ideas. While computational environments offer significant potential in terms of remote, information-enhanced working, important barriers also exist with regard to their responsiveness and accessibility. Much of the nuance and subtlety of communication that goes into creative discussion is lost when filtered through a digital interface. Hong et al. [58] have addressed the enablers and barriers that exist in architectural design collaboration, with a specific focus on the use of avatars to bolster co-presence and immersion. For architecture, where scale is critical, this is a particularly important consideration for future Virtual Reality (VR) and Augmented Reality (AR) development. Acikgoz [48] presents a model to guide and structure an architectural design studio experience, by means of which students communicate their design thinking and explore their solution ideas for the sake of improving their learning quality through the process. The model is also aimed to help instructors controlling and monitoring the whole process, based on defined criteria.

By assessing the interlinking among design moves or design decisions made by students in the process, Goldschmidt and Tatsa [55] provided empirical evidence about the cognitive mechanism responsible for the generation of "good" or "very good" ideas. It is from these kinds of ideas from which creativity may flourish. While these researchers do not explore the contents of the ideas themselves, they evaluate them quantitatively in order to identify connections between the quality of the final design projects and the ideas that leaded their development. Most meaningful ideas were found to have a significant larger number of links than other less important ideas. Even though this study was in relation to individual projects, they encompassed input from peers, visitors and instructors. No distinction was made in the analysis about where ideas came from, but the fact students 
were typically responsible for two thirds of the ideas related to their projects is illustrative of the highly collaborative nature of the architectural design studio.

\subsubsection{Shared Mental Models}

While we have addressed cognitive approaches and self-reflection as part of Category II, an important dimension in the collaborative setting is how understanding of a design problem is shared across the actors or participants. As for the models relating to problems and processes, this encompasses the use and adaptation of stimuli. Choi and Kim [54] describe the utilization of team-based learning (TBL) in a shared "digital world" to provide a conduit for the delivery of stimuli and scope for consistent reflection. This involves exposure to shared stimuli and set activities to ensure the co-evolution of ideation through the design process. While this is particularly concerned with the challenges of digital collaboration, the structuring of design processes with an appropriate balance between collective and individual activity can hold important lessons for any creative setting with a social dimension, such as the architectural design studio. As part of a model to guide the design activity in this setting, Acikgoz [48] uses the Collaborative Sketching (C-sketch) as a method in support of a diversity of idea generation carried out in teams. The technique enforces the possibility of articulating verbal and graphic information during the conceptual phase of the design process among the team members, while it increases the chances to produce more creative outcomes.

\subsection{Category IV: Information Representation}

Effective access and use of relevant information is essential to creative working in technical settings. This can encompass the types of stimuli used to enhance ideation, the background knowledge necessary to support ideation, or the representation of ideas and concepts. The tools used to manage these and how information is subsequently manipulated are the key concerns identified in this category.

\subsubsection{Tools for Information Representation}

Information can relate to the user and context as well as stimuli and background technical information. Hong et al. [60] address the role that virtual bodies (avatars) play in ideation. Architectural design students scored their ability to find new forms and functions with results suggesting that avatars can promote exploratory creativity in the digital environment. Choi and Kim [54] address the ways in which stimuli can generate thinking expansion. This is focused on the level of abstraction provided during brainstorming and problem solving, with the authors suggesting that this can be particularly effective in the digital context. Goldschmidt and Tatsa [55] employ the Linkography notation tool to explore the relationship between critical ideas and the number of links they establish with other ideas generated during the design process. Although labor demanding, the resulting graph enabled to get a precise overview of the produced pattern of links among all the ideas. In this sense, Linkography was beneficial for differentiating between different patterns of linking, which reflected the students' individual style of designing.

Bhattacharya et al. [50] proposed a virtual scenario where they developed "unconventional virtual environments (UVEs)" for the sake of enhancing conceptual blending and "extracting local distance" to encourage tolerance of ambiguity during design problem solving, with the purpose to promote creativity. In UVEs, architectural concepts, programmable architecture, freeform styling and time-based architecture were paired with virtual reality and computational techniques from complexity sciences. A method based on the automated extraction of features of image data in architecture was employed, characterized by dissolving lines, line segments, and perspective foreshortening to see the impact on judgement suspension and tolerance of ambiguity. 


\subsubsection{Manipulation of Information}

As set out in the information processing theme above, access to knowledge and information is essential to ideation in technical contexts. The ability to access and interact with information in a responsive manner is critical for focused, fluid ideation. As digital interfaces continue to evolve, they become increasingly dynamic. Hong and Lee [59] seek to understand the effectiveness of virtual users in creative working, particularly in relation to responsiveness of the virtual environment. Self-evaluation studies conducted with architectural students in a computer-aided architectural design course found that these encouraged more unexpected and physical functions of design solutions, and that increasing responsiveness of the environment led to improved diversity of ideas and quality of evaluation. Cho [52] investigated mental rotation as a domain-specific spatial ability. Accordingly, students were requested to observe three-dimensional (3D) images and match them with other images that were rotated spatially. A basic assumption was that the architecture domain-specific spatial ability is concerned with the skills to transform 2D architectural information into 3D or otherwise. The ability to generate and rotate mental images was investigated in regard to the capacity to produce creative designs. The awareness and ability to manipulate information need not relate only to technical resources or stimuli resources.

The broader environmental, situational, and process-related information considered essential to metacognitive frameworks described in Category II above is another important factor for consideration in this respect. Kavousi et al. [62] assert that metacognitive awareness has a fundamental role to play in design idea generation and solution development, as well as in the creative process in design. Their resulting model is based on a study that assessed the metacognitive process in terms of: reflective process control measured by situational actions, the environment and personal feelings; reflective process knowledge, evaluated by task-awareness, and cognitive strategies knowledge; and reflective process monitoring, measured personal feeling monitoring and situation actions. These all require characteristics and properties to be identified and understood, with a view to making the adjustments and corrections that will maximize performance in the creative context.

\subsection{Category V: Measuring Ideation and Creativity}

The design domain, and the architectural field specifically, offers a suitable context to assess creativity. Problems in this context are often ill-structured, open-ended, and have a variety of possible pathways to solutions. Hence, the relevant papers identified in this study were analyzed with regard to the categories as follows.

\subsubsection{Assessment of Creative Processes and Outcomes}

Many of the papers reviewed in this study consider the assessment of creative outputs to discuss critical issues related to the architectural design studio activity. It is important to consider how such measures, such as diversity, novelty and originality, can be adapted based on the particular challenges of the architectural design studio. For example, Choi and Kim [53] augment measures of novelty and familiarity with a "third element" that addresses ambiguous elements, such as obviousness and communication and observation in order to capture the behavioral aspects that accompany creative activity. Development of triangulated approaches such as this is worthy of consideration in highly social and dynamic spaces. For Hargrove and Nietfeld [57], assessment played an important role for tracking students' conceptual understanding about their metacognitive process, the construction of a mental model for a creative approach to design problem solving. These researchers assessed students' creative and metacognitive thinking through their final design project. The performance-based project requested from students to build a personal view of their design process with an emphasis on their creative thought processes. The evaluation process followed the consensual assessment technique, where independent assessments were made by design experts for technical as well as creative and metacognitive dimensions of the design thought model, and the produced outcomes. Findings endorse the inclusion of 
formalized training in metacognitive approach that promote creative problem solving, i.e., associative thinking.

Grover et al. [56] assessed the aid provided by typology at three major phases of the design process. An exploration of the frame definition phase of the design project showed that retrieving relevant features and identifying metaphorical typologies based on cultural, contextual or experiential phenomenon was challenging for most students. Few participants were able to establish relations between abstract ideas and typical situations. An assessment of the concept design stage showed that most participants produced simple diagrams of precedents and types, while most students had difficulties to reduce the level of detail of their drawings to find shared features with other precedents. At the detail design stage, it was easier to understand and apply ideas from more elemental typologies than from abstract concepts. Peers and guest teachers did not have a relevant contribution in any phase. Acikgoz [48] showed that structuring the architectural process has a large influence on the overall consistency between design thinking, and the ideas and solutions generated. He assessed learning quality attained during design team collaboration, which was based on rubrics that included problem definition, idea generation, connection and integration among ideas, and adaptation to the task at hand. Casakin and Kreitler [51] dealt with the relationship between the assessment of creativity in design problem solving and the level of expertise of the evaluator. The aim was to unveil whether design students and teachers share a similar understanding of creativity. Hence, factors critical for the assessment of creativity in architectural design were considered. These included fluency, elaboration, flexibility, and originality, which are seen to be the essence of creativity in every domain. Additional four factors for the assessment of creativity in the architectural domain were usefulness, fulfilment of design requirements, aesthetic aspects, and the context of the design outcome. Focusing on differences, students were found to center on operational aspects, and teachers were seen to pay more attention to innovative aspects. However, in general, a high match was found between students and teachers in the way that they assess creativity, and, therefore, these researchers suggested that self-assessment is a reliable and legitimate method of evaluation.

\subsubsection{Assessment of Personal Abilities}

In some respects, self-assessment in relation to creativity is less contentious. It does not require third party judgement and can provide insights on important characteristics such as confidence, perception and practice. In relation to students, the diary approach adopted by Choi and Kim [54] is illustrative of the benefits of multiple data points to develop insights on how teams navigate the design process -in their case, how understanding of how an abstract task in the digital context could help with reframing problems for enhanced ideation. Cho [52] evaluated freshman architecture and interior design majors' creativity, spatial ability, and visual cognitive style using the Torrance Tests of Creative Thinking (TTCT), Mental Rotation Test, Paper Folding Test, the Architectural Spatial Ability Test, and the Object-Spatial Imagery Questionnaire, and compared with one another and with the final scores obtained in the design studio. Findings indicated no correlations between studio course score and these measures. However, a positive correlation was found between general spatial abilities and visual cognitive styles. These results suggested that it is not possible to measure or predict design studio performance by creativity, spatial ability, and visual cognitive style. The findings stress the need to propose measurement criteria of domain-specific creativity and spatial ability, and the importance of holistic understanding of student abilities in architectural design education.

Mahmoud et al. [63] who investigated the relation between tolerance of ambiguity and creativity in architectural design, found a significant relation between divergent thinking ability (measured by the Torrance Tests of Creative Thinking-TTCT), and student tolerance to ambiguity and uncertainty. However, no relation was found between the design studio project score, associated to convergent thinking abilities, and tolerance of ambiguity. Moreover, no relation was found between students' grades and their divergent 
thinking abilities (TTCT scores). In a study that aimed at encouraging the combination of different ideas, Suh and Cho [64] investigated the domain-specific relation between enhancement of creative performance, and individual cognitive styles. They found that, when aided by a structured combinational approach, the individual differences in cognitive styles affected students' creative performances. The more intuitive ones managed to produce a pool of more creative self-generated ideas at the initial stages of the process.

\section{Discussion}

The systematic literature review focused on the state of the art in studies on creativity carried out in the context of the architectural design studio. The findings provide a holistic description of the key themes identified as important mainly at the early stages of the design process, also known as the conceptual phase, which is the most creative of the entire design process. In this section the results are discussed in three parts: (1) critical issues in the future of design creativity; (2) promoting design creativity in the architectural design studio; and (3) limitations of the study.

\subsection{Critical Issues in the Future of Design Creativity}

After an agreement on the themes that emerged from the analysis of the papers was reached by the two authors, these were organized into higher level categories. These reflected the main groupings under which research in this area can be identified and classified, and facilitated comparing and establishing connections among the papers. Based on the proposed framework, an overview of the emerging issues for creativity in the architectural design studio is discussed.

In terms of pedagogy, a greater focus on project structure and the selection of appropriate strategies and methods in the different phases of the design process was highlighted as critical to the delivery of high-quality learning experiences, e.g., $[50,57,62,65]$. This is closely related to aspects of cognitive approach, where an emphasis on metacognition, spatial information processing, self-reflection, and awareness of context in the design process are significant areas of current interest and exploration, e.g., $[49,55,58,65]$. These internal considerations about the mind of the designer compliment the external factors concerned with interaction and socialization, which are integral to the studio experience. This is generally viewed to be a positive influence on creative activity, e.g., [59], although how knowledge can be more effectively communicated and shared in design teams, e.g., [49,55], both real and virtual, is an issue with further scope for investigation. One highlighted means to deliver enhanced socialization is through technological solutions, and this equally applies to information representation. Accessing and sharing knowledge effectively are key concerns for creative work in design studio settings, as well as for some of the emerging insights in representation via avatars, e.g., [61] or virtual scenarios, e.g., [51], drawing on previous knowledge and ideas, e.g., [56], the utilization of abstract stimuli, e.g., [55], as well as the manipulation and transformation of spatial information, e.g., [53]. These point to new and promising kinds of working while engaging with the design activity that can only be achieved via computational and visualization tools. Finally, measuring ideation and creative activity is a long-standing concern for research in creativity, including process, outcome, and the designer. The literature in relation to the architectural design studio shows a leaning towards qualitative approaches including the use of self-evaluation diaries and questionnaires focusing on students' personal views of their processes, e.g., [58], as well as quantitative approaches concerning domain-general creativity measures assessing design outcomes, e.g., [52]. Their employment seems to be appropriate considering the nature of the design discipline. However, the combination of domain-general established creativity measures with more observational and interpretive tools related to the architectural design domain may offer further possibilities to capture the full scope of the studio creative experience. Further work to explore the configuration and application of these would be a worthy endeavor. 


\subsection{Promoting Design Creativity in the Architectural Design Studio}

Our initial research question "What creativity and ideation issues exist during design activity carried out in the architectural studio?" was to understand what the current state of the art on the topic is, with the intention of gaining an insight onto how students working in these learning environments can be better supported to enhance design creativity. Educating students in the design studio to become architects is composed of many different goals from which the ultimate one is to simulate real practice by trial and error [67]. The main pedagogical model with regards to this is Project Based Learning (PBL) $[68,69]$. However, while this model is concerned with many different issues, only one centers on creativity. This means that intervention programs aimed at encouraging creativity are required to invest additional efforts in this direction to help students think unconventionally, e.g., [51] in order to deal with ambiguity and uncertainty, e.g., [64]. Consequently, it is suggested that students should be trained in a more focused, oriented way to develop their creative abilities in the domain irrespective of the other activities that are necessary to become architects, e.g., [58]. With respect to this, in addition to the regular activities carried out in the design studio, workshops that are purposefully intended to stimulate and promote creative thinking are a particularly promising means to enhance creative skills to students. In terms of how best to deliver such workshops, a number of the papers stress how this can be formalized and developed, e.g., [51,57]. Studies like these help identify particular aspects of creativity (e.g., cognition, collaboration, use of tools, etc.), and provide a clearly defined structure to support students in reaching creative solutions. Considering such approaches to train design students may provide learners with specific experiences and skills that later on can be employed to maximize creative performance in more generic PBL scenarios. In addition to this, it is important to continue increasing awareness of design creativity issues for architectural design educators. Through continued research activity that includes participation in conferences and educator networks, as well as affiliation with accreditation bodies, best practices and innovations for curriculum development can be shared and implemented more widely.

\subsection{Limitations of the Study}

Like any research study, systematic reviews have limitations, many of which emerge from the quality and quantity of the source studies, and the quality of the systematic review procedures [36]. While these types of reviews aim to provide an objective view of the literature, there are areas such as selection of sources, and screening of papers where subjective decisions can be influenced by bias. In this study, in particular, the nature of much of the research around the topic of creativity in the architectural design studio meant that a thorough inspection and review was necessary to reach full agreement on a strictly relevant pool of papers. Additionally, while there is a great deal of literature relating to creativity, there is a relatively limited amount concerned with its role in the architectural design studio. This has necessitated the augmentation of the optimized search string used in Summon, with additional searches across sources based on the experience of the researchers. These are extremely resource intensive and time-consuming tasks that demand high motivation and persistence, which is not something to be taken for granted.

\section{Conclusions}

This paper reports on a systematic review process that, from an initial pool of 717 results, resulted in analysis of 17 papers according to five key categories of analysis: pedagogy, cognitive approach, interaction and socialization, information representation, measuring ideation and creativity, which encompassed 11 themes. These broadly reflect the issues of creative activity in design education domain. The current study revealed that the identified issues pertaining to the architectural design studio highlighted several interesting dichotomies: it is highly collaborative while inviting individual expression; it invites the use of a wide range of stimuli within a context of established typographies; it is well-suited to the use of advanced visualization technologies, but relies on conventional sketching and 
drawing practices; and increasing structure is recommended to support activities despite the recognition for individual reflection and metacognition. In summary, the literature around creativity in the architectural design studio has attained some level of maturity but there is still much to be done. This becomes evident when comparing the large number of studies in literature on the topic in the fields of product and engineering design, many of which focused on creative design approaches, or the design curriculum. For example, Loewy [70] investigated techniques and methods that showed to be helpful as a catalyst for promoting innovation and creativity in the industrial design studio. Vyas et al. [71] studied two industrial design departments for the aim of developing collaborative support in design studio environments. A main focus was set to understand experiential and inspirational aspects related to creative design practices. Kellam et al. [72] proposed a curricular model for the engineering education field: the Synthesis and Design Studio. To this end, they investigated the role of creativity and interdisciplinarity in curriculum integration of meta-learning in the engineering design studio. Richards [73] also explored the nature of and conditions for supporting creativity, and how to foster it in engineering education. He presented several courses conceived to teach engineering studies to become innovators.

In the era of a global pandemic, communicating and sharing information in an effective and understandable way has become more relevant than ever. This raises critical questions regarding how the traditional architectural design studio should be rethought to fit new needs. Based on the systems tools that have been discussed in this paper, it is suggested that some of these directions will be considered in future research. A main challenge will be to continue developing both digital and virtual environments that could emulate and even improve the advantages of teaching in the traditional design studio environment. A major aim should be investigating how to support the flow of communication, information exchange and interaction between students and instructors. Developing more robust digital tools so that 2D and 3D information could be better (re)presented, integrated, and manipulated, e.g., $[53,60]$ can contribute to this end. For example, research aligned with Bhattacharya et al. [50] can contribute to an easier navigation in unconventional virtual environments and improve cognitive perception in support of spatial creativity. Investigations related to Hong et al. [59] and Acikgoz [49] can enhance individual or group interactions and team collaboration during design critique sessions, whereas works following Choi and Kim [55] may aid in issues concerned with team-based learning from remote distance. Another promising direction might consist in developing further digital libraries containing architectural design information, i.e., architectural precedents, typological knowledge, design strategies, and other design issues [57] to support students' design creative problem-solving skills during the different phases of the design process.

As our understanding of creativity continues to evolve, findings from disciplines such as neuroscience, psychology, and sociology will inform future cognitive models and tools to support collaborative design activity. Emerging approaches from other fields such as biology (biomimetics) and computer science (generative design, AI) that have not manifested themselves in the results of the systematic review can be anticipated to impact on how creativity is nurtured in the future. These new concepts and approaches will still require to be framed and developed in such a way that they are practical, feasible and beneficial for application in the architectural design studio. The themes and issues presented in this study provide a basis for such investigations, and to support the next generation of creative educators and architects.

Author Contributions: Conceptualization, H.C. and A.W.; methodology, H.C. and A.W.; validation, H.C. and A.W.; formal analysis, H.C. and A.W.; investigation, H.C. and A.W.; writing-original draft preparation, H.C. and A.W.; writing - review and editing, H.C. and A.W. All authors have read and agreed to the published version of the manuscript.

Funding: This research received no external funding.

Informed Consent Statement: Not applicable.

Conflicts of Interest: The authors declare no conflict of interest. 


\section{Appendix A}

\begin{tabular}{|c|c|c|c|}
\hline Paper No. & Authors & Year & Title \\
\hline 1 & Açikgöz [48] & 2015 & $\begin{array}{c}\text { Uncovering creativity: Structuring experience in architectural } \\
\text { design studio }\end{array}$ \\
\hline 2 & Asefi [49] & 2018 & $\begin{array}{c}\text { Effects of active strategic teaching model (ASTM) in creative and critical } \\
\text { thinking skills of architecture students }\end{array}$ \\
\hline 3 & Bhattacharya [50] & 2016 & The Proto-Fuse project: Methods to boost creativity for architects \\
\hline 4 & Casakin [51] & 2007 & $\begin{array}{c}\text { Correspondences and divergences between teachers and students in the } \\
\text { evaluation of design creativity in the design studio }\end{array}$ \\
\hline 5 & Cho [52] & 2017 & $\begin{array}{c}\text { An investigation of design studio performance in relation to creativity, } \\
\text { spatial ability, and visual cognitive style }\end{array}$ \\
\hline 6 & Choi [53] & 2016 & $\begin{array}{l}\text { The potential of reasoning methods as a teaching strategy supporting } \\
\text { students' creative thinking in architectural design }\end{array}$ \\
\hline 7 & Choi [54] & 2018 & $\begin{array}{l}\text { Using the digital context to overcome design fixation: A strategy to } \\
\text { expand students' design thinking }\end{array}$ \\
\hline 8 & Goldschmidt [55] & 2005 & How good are good ideas? Correlates of design creativity \\
\hline 9 & Grover [56] & 2018 & $\begin{array}{l}\text { The typological learning framework: The application of structured } \\
\text { precedent design knowledge in the architectural design studio }\end{array}$ \\
\hline 10 & Hargrove [57] & 2015 & The impact of metacognitive instruction on creative problem solving \\
\hline 11 & Hong [58] & 2016 & $\begin{array}{l}\text { Enablers and barriers of the multi-user virtual environment for } \\
\text { exploratory creativity in architectural design collaboration }\end{array}$ \\
\hline 12 & Hong [59] & 2019 & $\begin{array}{c}\text { Behavioural responsiveness of virtual users for students' creative } \\
\text { problem-finding in architectural design }\end{array}$ \\
\hline 13 & Hong [60] & 2019 & $\begin{array}{l}\text { Virtual vs. actual body: Applicability of anthropomorphic avatars to } \\
\text { enhance exploratory creativity in architectural design education }\end{array}$ \\
\hline 14 & Kowaltowski [61] & 2010 & $\begin{array}{c}\text { Methods that may stimulate creativity and their use in architectural } \\
\text { design education }\end{array}$ \\
\hline 15 & Kavousi [62] & 2020 & Modeling metacognition in design thinking and design making \\
\hline 16 & Mahmoud [63] & 2020 & $\begin{array}{c}\text { The relationship between tolerance of ambiguity and creativity in } \\
\text { architectural design studio }\end{array}$ \\
\hline 17 & Suh [64] & 2018 & $\begin{array}{l}\text { Analyzing individual differences in creative performance: A case study } \\
\text { on the combinational ideation method in the interior design process }\end{array}$ \\
\hline
\end{tabular}

\section{References}

1. Gero, J.S. Creativity, Emergence and Evolution in Design. Knowl. Based Syst. 1996, 9, 435-448. [CrossRef]

2. Simon, H.A. The Sciences of the Artificial; MIT Press: Cambridge, MA, USA, 2019.

3. Goel, V. Sketches of Thought; MIT Press: Cambridge, MA, USA, 1995.

4. Rittel, H.; Webber, M. Planning Problems Are Wicked Problems. In Developments in Design Methodology; Cross, N., Ed.; John Wiley \& Sons: New York, NY, USA, 1984; pp. 135-144.

5. Cross, N. Expertise in Design: An Overview. Des. Stud. 2004, 25, 427-441. [CrossRef]

6. Dorst, K.; Cross, N. Creativity in the Design Process: Co-Evolution of Problem-Solution. Des. Stud. 2001, 22, 425-437. [CrossRef]

7. Gonçalves, M.; Cardoso, C.; Badke-Schaub, P. What Inspires Designers? Preferences on Inspirational Approaches during Idea Generation. Des. Stud. 2014, 35, 29-53. [CrossRef]

8. Rojas, J.P.; Tyler, K.M. Measuring the Creative Process: A Psychometric Examination of Creative Ideation and Grit. Creat. Res. J. 2018, 30, 29-40. [CrossRef]

9. Runco, M.A.; Jaeger, G.J. The Standard Definition of Creativity. Creat. Res. J. 2012, 24, 92-96. [CrossRef]

10. Snider, C.; Dekoninck, E.; Culley, S. Beyond the Concept: Characterisations of Later-Stage Creative Behaviour in Design. Res. Eng. Des. 2016, 27, 265-289. [CrossRef]

11. Wodehouse, A.; Ion, W. Information and Ideas: Concept Design in Three Industrial Contexts. J. Des. Res. 2011, 9, 390-404. [CrossRef]

12. Chakrabarti, A.; Morgenstern, S.; Knaab, H. Identification and Application of Requirements and Their Impact on the Design Process: A Protocol Study. Res. Eng. Des. 2004, 15, 22-39. [CrossRef]

13. Sarkar, P.; Chakrabarti, A. Assessing Design Creativity. Des. Stud. 2011, 32, 348-383. [CrossRef]

14. Guilford, J.P. The Nature of Human Intelligence; McGraw-Hill: New York, NY, USA, 1967.

15. Torrance, E.P. Torrance Tests of Creative Thinking; Personnel Press: Lexington, MA, USA, 1974.

16. Amabile, T.M. Creativity in Context: Update to the Social Psychology of Creativity; Routledge: New York, NY, USA, 2018.

17. Baer, J. The Case for Domain Specificity of Creativity. Creat. Res. J. 1998, 11, 173-177. [CrossRef]

18. Hong, E.; Milgram, R.M. Creative Thinking Ability: Domain Generality and Specificity. Creat. Res. J. 2010, 22, 272-287. [CrossRef] 
19. Kaufman, J.C.; Baer, J. Creativity across Domains: Faces of the Muse; Lawrence Erlbaum Associates: Mahwah, NJ, USA, 2005.

20. Casakin, H.; Davidovitch, N.; Milgram, R.M. Creative Thinking as a Predictor of Creative Problem Solving in Architectural Design Students. Psychol. Aesthet. Creat. Arts 2010, 4, 31. [CrossRef]

21. Chan, C.-S. Style and Creativity in Design; Springer: Cham, Switzerland, 2015; Volume 17.

22. Goldschmidt, G.; Casakin, H.; Avidan, Y.; Ronen, O. Three Studio Critiquing Cultures: Fun Follows Function or Function Follows Fun? Des. Think. Res. Symp. 2014. [CrossRef]

23. Boucharenc, C.G. Research on Basic Design Education: An International Survey. Int. J. Technol. Des. Educ. 2006, 16, 1-30. [CrossRef]

24. Casakin, H.; Kreitler, S. Correspondences and Divergences in Creativity Evaluations between Architects and Students. Environ. Plan. Des. Des. B 2008, 35, 666-678. [CrossRef]

25. Crowther, P. Understanding the Signature Pedagogy of the Design Studio and the Opportunities for Its Technological Enhancement. J. Learn. Des. 2013, 6, 18-28. [CrossRef]

26. Curry, T. A Theoretical Basis for Recommending the Use of Design Methodologies as Teaching Strategies in the Design Studio. Des. Stud. 2014, 6, 632-646. [CrossRef]

27. Hatcher, G.; Ion, W.; Maclachlan, R.; Sheridan, M.; Simpson, B.; Wodehouse, A. Evolving Improvised Ideation from Humour Constructs: A New Method for Collaborative Divergence. Creat. Innov. Manag. 2018, 27, 91-101. [CrossRef]

28. Goldschmidt, G.; Smolkov, M. Variances in the Impact of Visual Stimuli on Design Problem Solving Performance. Des. Stud. 2006, 27, 549-569. [CrossRef]

29. Petticrew, M.; Roberts, H. Systematic Reviews in the Social Sciences: A Practical Guide; Blackwell Publishing: Malden, MA, USA, 2006.

30. Robinson, P.; Lowe, J. Literature Reviews vs Systematic Reviews. Aust. New Zealand J. Public Health 2015, 39, 103. [CrossRef] [PubMed]

31. Salleh, N.; Mendes, E.; Grundy, J. Empirical Studies of Pair Programming for CS/SE Teaching in Higher Education: A Systematic Literature Review. IEEE Trans. Softw. Eng. 2010, 37, 509-525. [CrossRef]

32. Tranfield, D.; Denyer, D.; Smart, P. Towards a Methodology for Developing Evidence-Informed Management Knowledge by Means of Systematic Review. Br. J. Manag. 2003, 14, 207-222. [CrossRef]

33. Kelly, M.; Morgan, A.; Ellis, S.; Younger, T.; Huntley, J.; Swann, C. Evidence Based Public Health: A Review of the Experience of the National Institute of Health and Clinical Excellence (NICE) of Developing Public Health Guidance in England. Soc. Sci. Med. 2010, 71, 1056-1062. [CrossRef] [PubMed]

34. Dickson, K.; Sutcliffe, K.; Rees, R.; Thomas, J. Gaps in the Evidence on Improving Social Care Outcomes: Findings from a Meta-Review of Systematic Reviews. Health Soc. Care Community 2017, 25, 1287-1303. [CrossRef] [PubMed]

35. Morelock, J.R. A Systematic Literature Review of Engineering Identity: Definitions, Factors, and Interventions Affecting Development, and Means of Measurement. Eur. J. Eng. Educ. 2017, 42, 1240-1262. [CrossRef]

36. Borrego, M.; Foster, M.J.; Froyd, J.E. Systematic Literature Reviews in Engineering Education and Other Developing Interdisciplinary Fields. J. Eng. Educ. 2014, 103, 45-76. [CrossRef]

37. Li, Q.; Ma, X. A Meta-Analysis of the Effects of Computer Technology on School Students' Mathematics Learning. Educ. Psychol. Rev. 2010, 22, 215-243. [CrossRef]

38. Cook, D.A.; West, C.P. Conducting Systematic Reviews in Medical Education: A Stepwise Approach. Med. Educ. 2012, 46, 943-952. [CrossRef]

39. Schmid, R.F.; Bernard, R.M.; Borokhovski, E.; Tamim, R.; Abrami, P.C.; Wade, C.A.; Surkes, M.A.; Lowerison, G. Technology's Effect on Achievement in Higher Education: A Stage I Meta-Analysis of Classroom Applications. J. Comput. High. Educ. 2009, 21, 95-109. [CrossRef]

40. Tondeur, J.; van Braak, J.; Sang, G.; Voogt, J.; Fisser, P.; Ottenbreit-Leftwich, A. Preparing Pre-Service Teachers to Integrate Technology in Education: A Synthesis of Qualitative Evidence. Comput. Educ. 2012, 59, 134-144. [CrossRef]

41. Borrego, M.; Newswander, L.K. Characteristics of Successful Cross-Disciplinary Engineering Education Collaborations. J. Eng. Educ. 2008, 97, 123-134. [CrossRef]

42. Kitchenham, B.A.; Brereton, P.; Turner, M.; Niazi, M.K.; Linkman, S.; Pretorius, R.; Budgen, D. Refining the Systematic Literature Review Process-Two Participant-Observer Case Studies. Empir. Softw. Eng. 2010, 15, 618-653. [CrossRef]

43. Streveler, R.A.; Borrego, M.; Smith, K.A. 9: Moving from the Scholarship of Teaching and Learning to Educational Research: An Example From Engineering. Improv. Acad. 2007, 25, 139-149. [CrossRef]

44. Borrego, M.; Douglas, E.P.; Amelink, C.T. Quantitative, Qualitative, and Mixed Research Methods in Engineering Education. J. Eng. Educ. 2009, 98, 53-66. [CrossRef]

45. Koro-Ljungberg, M.; Douglas, E.P. State of Qualitative Research in Engineering Education: Meta-Analysis of JEE Articles, 2005-2006. J. Eng. Educ. 2008, 97, 163-175. [CrossRef]

46. Lou, Y. Understanding Process and Affective Factors in Small Group Versus Individual Learning with Technology. J. Educ. Comput. Res. 2004, 31, 337-369. [CrossRef]

47. Tamim, R.M.; Bernard, R.M.; Borokhovski, E.; Abrami, P.C.; Schmid, R.F. What Forty Years of Research Says About the Impact of Technology on Learning: A Second-Order Meta-Analysis and Validation Study. Rev. Educ. Res. 2011, 81, 4-28. [CrossRef] 
48. Açikgöz, E.K. Uncovering Creativity: Structuring Experience in Architectural Design Studio. Open House Int. $2015,40,12-21$. [CrossRef]

49. Asefi, M.; Imani, E. Effects of Active Strategic Teaching Model (astm) in Creative and Critical Thinking Skills of Architecture Students. Archnet IJAR Int. J. Archit. Res. 2018, 12, 209-222. [CrossRef]

50. Bhattacharya, J.; Hakak, A.M.; Biloria, N.; Venhari, A.A. The Proto-Fuse Project: Methods to Boost Creativity for Architects. Int. J. Des. Creat. Innov. 2016, 4, 206-221.

51. Casakin, H.; Kreitler, S. Correspondences and Divergences between Teachers and Students in the Evaluation of Design Creativity in the Design Studio. Environ. Plan. B Plan. Des. 2008, 35, 666-678. [CrossRef]

52. Cho, J.Y. An Investigation of Design Studio Performance in Relation to Creativity, Spatial Ability, and Visual Cognitive Style. Think. Ski. Creat. 2017, 23, 67-78. [CrossRef]

53. Choi, H.H.; Kim, M.J. The Potential of Reasoning Methods As a Teaching Strategy Supporting Students' Creative Thinking in Architectural Design. Archnet IJAR Int. J. Archit. Res. 2016, 10, 6-20. [CrossRef]

54. Choi, H.H.; Kim, M.J. Using the Digital Context to Overcome Design Fixation: A Strategy to Expand Students' Design Thinking Archnet IJAR Int. J. Archit. Res. 2018, 12, 228-240. [CrossRef]

55. Goldschmidt, G.; Tatsa, D. How Good Are Good Ideas? Correlates of Design Creativity. Des. Stud. 2005, 26, 593-611. [CrossRef]

56. Grover, R.; Emmitt, S.; Copping, A. The Typological Learning Framework: The Application of Structured Precedent Design Knowledge in the Architectural Design Studio. Int. J. Technol. Des. Educ. 2018, 28, 1019-1038. [CrossRef]

57. Hargrove, R.A.; Nietfeld, J.L. The Impact of Metacognitive Instruction on Creative Problem Solving. J. Exp. Educ. 2015, 83, 291-318. [CrossRef]

58. Hong, S.W.; Jeong, Y.; Kalay, Y.E.; Jung, S.; Lee, J. Enablers and Barriers of the Multi-User Virtual Environment for Exploratory Creativity in Architectural Design Collaboration. CoDesign 2016, 12, 151-170. [CrossRef]

59. Hong, S.W.; Lee, Y.G. Behavioural Responsiveness of Virtual Users for Students' Creative Problem-Finding in Architectural Design. Archit. Sci. Rev. 2019, 62, 238-247. [CrossRef]

60. Hong, S.W.; Park, J.; Cho, M. Virtual vs. Actual Body: Applicability of Anthropomorphic Avatars to Enhance Exploratory Creativity in Architectural Design Education. Archit. Sci. Rev. 2019, 62, 520-527. [CrossRef]

61. Kowaltowski, D.C.C.K.; Bianchi, G.; de Paiva, V.T. Methods That May Stimulate Creativity and Their Use in Architectural Design Education. Int. J. Technol. Des. Educ. 2010, 20, 453-476. [CrossRef]

62. Kavousi, S.; Miller, P.A.; Alexander, P.A. Modeling Metacognition in Design Thinking and Design Making. Int. J. Technol. Des. Educ. 2020, 30, 709-735. [CrossRef]

63. Mahmoud, N.E.; Kamel, S.M.; Hamza, T.S. The Relationship between Tolerance of Ambiguity and Creativity in Architectural Design Studio. Creat. Stud. 2020, 13, 179-198. [CrossRef]

64. Suh, J.; Cho, J.Y. Analyzing Individual Differences in Creative Performance: A Case Study on the Combinational Ideation Method in the Interior Design Process. J. Inter. Des. 2018, 43, 9-23. [CrossRef]

65. Wright, A. Critical Method: A Pedagogy for Design Education. Des. Princ. Pract. Int. J. 2011, 5, 109-122. [CrossRef]

66. Lydon, M.; Garcia, A. A Tactical Urbanism How-To. In Tactical Urbanism; Springer: Washington, DC, USA, 2015 ; pp. 171-208.

67. Salama, A.M.; Wilkinson, N. Design Studio Pedagogy: Horizons For The Future; Urban International Press: Gateshead, UK, 2007.

68. Dym, C.L.; Agogino, A.M.; Eris, O.; Frey, D.D.; Leifer, L.J. Engineering Design Thinking, Teaching, and Learning. J. Eng. Educ. 2005, 94, 103-120. [CrossRef]

69. Lande, M.; Leifer, L. Difficulties Student Engineers Face Designing the Future. Int. J. Eng. Educ. 2010, 26, 271.

70. Loewy, A.F. Teaching Design Innovation: Methods for Promoting Innovation in the University Industrial Design Studio. In Proceedings of the Venture Well. Proceedings of Open, the Annual Conference; 2008; p. 149. Available online: https: / / citeseerx.ist.psu.edu/viewdoc/download?doi=10.1.1.485.5444\&rep=rep1\&type=pdf (accessed on 16 January 2021).

71. Vyas, D.; van der Veer, G.; Nijholt, A. Creative Practices in the Design Studio Culture: Collaboration and Communication. Cogn. Technol. Work 2013, 15, 415-443. [CrossRef]

72. Kellam, N.; Walther, J.; Costantino, T.; Cramond, B. Integrating the Engineering Curriculum Through the Synthesis and Design Studio. Adv. Eng. Educ. 2013, 3, 1-33.

73. Richards, L.G. Stimulating Creativity: Teaching Engineers to Be Innovators. In Proceedings of the FIE '98. 28th Annual Frontiers in Education Conference. Moving from 'Teacher-Centered' to 'Learner-Centered' Education, Tempe, AZ, USA, 4-7 November 1998; pp. 1034-1039. 